\title{
A field-oriented control method using the virtual currents for the induction motor drive
}

\author{
Cuong Dinh Tran', Tien Xuan Nguyen ${ }^{2}$, Phuong Duy Nguyen ${ }^{3}$ \\ ${ }^{1}$ Power System Optimization Research Group, Faculty of Electrical and Electronics Engineering, Ton Duc Thang \\ University, Ho Chi Minh City, Vietnam \\ ${ }^{2,3}$ Faculty of Electronics and Telecommunication, Saigon University, Vietnam
}

\begin{tabular}{l} 
Article Info \\
\hline Article history: \\
Received Aug 30, 2021 \\
Revised Oct 7, 2021 \\
Accepted Oct 15, 2021 \\
\hline
\end{tabular}

Keywords:

Estimated current Field-oriented control Induction motor Slip frequency Virtual sensor

\begin{abstract}
An improving field-oriented control technique without current sensors is proposed to control rotor speed for an induction motor drive. The estimated stator currents based on the slip frequency are used instead of feedback current signals in the field-oriented control (FOC) loop. The reference signals and the estimated currents through computation steps are used to generate the control voltage for the switching inverter. Simulations were performed in Matlab/Simulink environment at rated speed and low-speed range to demonstrate the method's feasibility. Through simulation results, the FOC method using virtual sensors has proved its effectiveness in ensuring the stable operation of the induction motor drive (IMD) over a wide speed range.
\end{abstract}

This is an open access article under the CC BY-SA license.

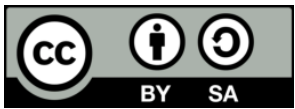

\section{Corresponding Author:}

Cuong Dinh Tran

Power System Optimization Research Group

Faculty of Electrical and Electronics Engineering

Ton Duc Thang University

19 Nguyen Huu Tho, District 7, Ho Chi Minh City, Vietnam

Email: trandinhcuong@tdtu.edu.vn

\section{NOMENCLATURE}

\begin{tabular}{|c|c|c|c|}
\hline$i_{S}^{S}$ & :Stator_current vector in $[\alpha, \beta]$ & $i_{m}$ & :Magnetizing_current \\
\hline$i_{R}^{S}$ & $\begin{array}{l}: \text { Rotor_current vector in }[\alpha, \\
\beta]\end{array}$ & $\omega_{m}$ & :Mechanical_angular speed \\
\hline$u_{S \alpha}, u_{S \beta}$ & :Stator_voltage in $[\alpha, \beta]$ & $\omega_{e n}$ & :Mechanical_angular speed of the encoder \\
\hline$u_{S x}, u_{S y}$ & :Stator_voltage in $[x, y]$ & $P$ & :Number of pole pair \\
\hline$u_{a}, u_{b}, u_{c}$ & :Stator_voltage in $[a, b, c]$ & $\Psi_{R}$ & :Nominal_rotor flux \\
\hline & :Flux_current & $\Psi_{R x}, \Psi_{R y}$ & :Rotor_flux in $[x, y]$ \\
\hline$i_{S y}$ & :Torque_current & $\Psi_{S x}, \Psi_{S y}$ & :Stator_flux in $[x, y]$ \\
\hline & & $\gamma$ & :Rotor_flux angle \\
\hline
\end{tabular}

\section{INTRODUCTION}

Asynchronous motor, which operates based on the electromagnetic induction principle, is one of the most popular electric machine types with a wide variety of industrial applications. Based on inverter technology and microprocessor technology development, the induction motor (IM) drive using modern control algorithms has expanded its operation scope into speed control applications [1]. Scalar control and 
vector control are the two major branches of IMD's speed control application. The Scalar control (Scl) method's basic principle is to keep the flux as a constant value when controlling the speed by adjusting the stator voltage according to the operating speed (V/f). Typical scalar methods with advantages of simple control algorithm, fast response, medium hardware are suitable for applications that do not require high precision [2]-[5].

Field-oriented control (FOC) is a typical modern control method in the vector control method group. FOC method is suitable for applications requiring high precision in speed and torque control [6], [7]. FOC technique converts the IM's complicated non-linear control structure into a linear control structure similar to the DC motor control technique. The three-phase stator current in the FOC technique is divided into two orthogonal components, including " $i_{s x}$ " and " $i_{s y}$ " in the $[x, y]$ rotating coordinate system, as in Figure 1 . The " $i_{s x}$ " component is used to keep the rotor flux as a constant value, and the "isy" component is applied to adjust the IM's torque [8]-[14]. Therefore the stator current plays a crucial role in the speed control of the FOC technique. If there is any failure of the current sensors during the operation, the performance of IMD's can be severely affected, which can cause the collapse of the total system [15]-[19].

Stability and reliability always are essential criteria of speed control in IMD systems. Therefore, in recent years, FOC methods without current sensors, called current sensorless (CSL), has been focused on research. Generally, virtual current signals are used instead of the measured current signals supplied to the FOC control loop in the CSL technique. The aim of CSL controllers is to ensure the stable operation of the IMD system in controlling the rotor speed without feedback current signal from sensors in various operating conditions.

In Barba et al. [20], the speed of IMD is controlled by the FOC method without any current sensors. In this method, an observer based on the typical Luenberger form receives current DC-link signals and the feedback rotor speed to estimate the reference voltages for motor speed control. The success of the method is determined through the stable operation of IMD under normal conditions. In [21], a fault-tolerant control is presented as a solution against the failure of current sensors. The estimated line-current generated from a Luenberger observer is used to replace the measured stator current to calculate the electrical torque and stator flux vector for the direct torque controller of IMD. Using estimated line-currents has ensured stable operation of IMD under current sensor fault states. In [22], A new CSL method is applied for estimating the stator current from the rotor flux variable and voltage signal in $[\alpha, \beta]$ coordinate. In this way, the speed of IM is controlled through the FOC loop with only a feedback speed signal of the encoder. The IMD system without current sensors could work stably and reliably under various operating conditions. Authors in [23] have proposed a method for virtual stator current estimation to replace the function of the measured currents in the speed control of IMD. The virtual current signals in this paper are estimated from the voltage signal of the DC bus and the feedback signal of the encoder. The proposed method has proven highly reliable when operating efficiently under load and no-load conditions over a wide speed range.

This paper proposes the virtual stator currents based on the slip frequency instead of feedback current signals in the FOC technique. The estimation algorithm uses machine parameters and virtual currents to generate the predicted voltage supplied to the inverter switching control. The feasibility of the technique will be demonstrated in various operating conditions in the Matlab/Simulink environment.

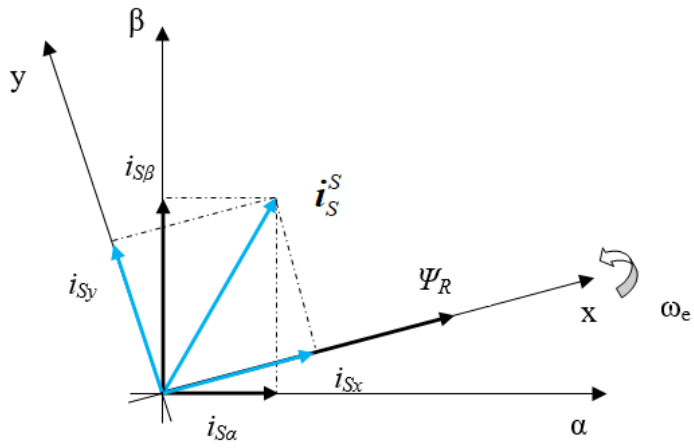

Figure 1. Vector control diagram

\section{FOC METHOD USING THE VIRTUAL CURRENT}

In this section, the operational structure of IMD systems using the FOC strategy is introduced in general. The mathematical equation of IMD is presented in detail in the rotating coordinate system. Then, a FOC method without current sensors (virtual currents) is proposed for the speed control of the IMD. 


\subsection{FOC technique in rotating coordinate system}

The FOC works based on projections on the axes of the $[x, y]$ rotating coordinate system corresponding to rotor flux angle and rotor flux speed [24]-[29]. The $i_{s x}$-component is used for controlling the magnetic current to keep the rotor flux as a setting value. The $i_{s y}$-component controls the electrical torque of IMD to obtain the setting motor speed. The operation mechanism of the IMD system using the typical FOC strategy is shown in the block diagram in Figure 2.

There are three sensors used in the typical FOC method for motor speed control, including a pair of current sensors and a speed encoder. Two-phase current signals in the $[a, b, c]$ coordinate is transformed to the $[\alpha, \beta]$ stationary coordinate by using Clark's formulas [17] in the FOC controller, as shown in (1).

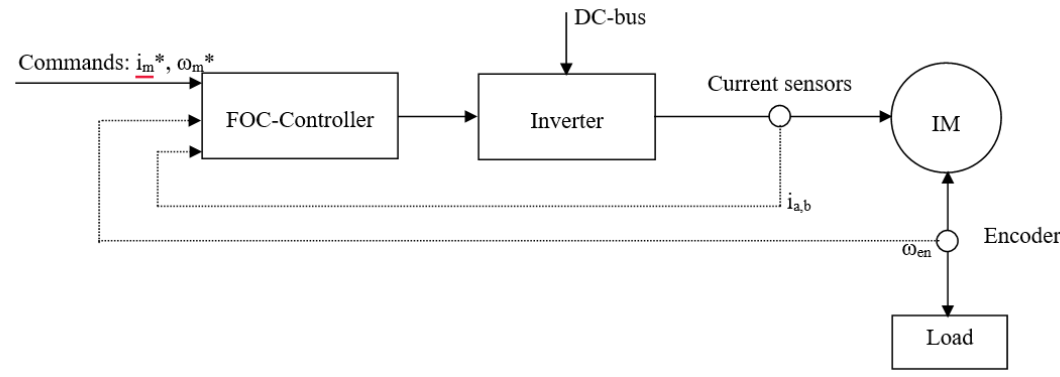

Figure 2. Block diagram of IMD using typical FOC

$$
\left[\begin{array}{l}
i_{S \alpha} \\
i_{S \beta}
\end{array}\right]=\left[\begin{array}{cc}
1 & 0 \\
\frac{1}{\sqrt{3}} & \frac{2}{\sqrt{3}}
\end{array}\right] \cdot\left[\begin{array}{l}
i_{a} \\
i_{b}
\end{array}\right]
$$

Next step, Park's formulas [17] are used to convert current vector components from $[\alpha, \beta]$ to $[x, y]$ coordinate, as shown in (2).

$$
\left[\begin{array}{l}
i_{S x} \\
i_{S y}
\end{array}\right]=\left[\begin{array}{cc}
\cos \gamma & \sin \gamma \\
-\sin \gamma & \cos \gamma
\end{array}\right] \cdot\left[\begin{array}{c}
i_{S \alpha} \\
i_{S \beta}
\end{array}\right]
$$

The $i_{S \alpha}, i_{S \beta}$ components combining a feedback motor speed signal is applied to determine the magnetic current and rotor flux angle.

The PI controllers use the deviation of the reference and actual signals to generate the reference voltage in $[x, y]$ rotating coordinate. The reverse Park's formulas are applied to convert this reference signal into the $[\alpha, \beta]$ stationary coordinate. Finally, the reference voltage is transformed back to the $[a, b, c]$ coordinate for the switching control pulse of the inverter.

\subsection{Current sensorless technique based on the rotor slip speed (Virtual currents)}

The relationship between voltage, current, and flux signals in IM is non-linear. The dynamic equations of IM in $[x, y]$ rotating coordinate are described in detail [30] as shown in:

$$
\begin{aligned}
& u_{S x}=R_{S} i_{S x}+\omega_{e} \psi_{S y}+\frac{d \psi_{S x}}{d t} \\
& u_{S y}=R_{S} i_{S y}+\omega_{e} \psi_{S x}+\frac{d \psi_{S y}}{d t} \\
& 0=R_{R} i_{R x}-\omega_{s l} \psi_{R y}+\frac{d \psi_{R x}}{d t} \\
& 0=R_{R} i_{R y}-\omega_{s l} \psi_{R x}+\frac{d \psi_{R y}}{d t}
\end{aligned}
$$


Where

$R_{S} / R_{R}:$ Stator/Rotor_resistance

$\omega_{s l} \quad:$ Rotor slip speed

$\omega_{e} \quad$ : Flux_speed

The rotor flux is kept as a constant value and has the same direction as the $\mathrm{x}$-axis of the coordinate corresponding to the FOC technique. The feature of rotor flux in the $[x, y]$ rotating coordinate system, as shown in follows:

$$
\left\{\begin{array}{l}
\psi_{R x}=\psi_{R}=\text { const } \\
\psi_{R y}=0
\end{array}\right.
$$

Using (7) into (3)-(6), we can receive in (8)-(10):

$$
\begin{aligned}
& u_{S x}=R_{S} i_{S x}-\omega_{e} L_{\sigma} i_{S y} \\
& u_{S y}=R_{S} i_{S y}+\omega_{e} L_{S} i_{S x}+L_{\sigma} \frac{d i_{S y}}{d t} \\
& \left\{\begin{array}{l}
\omega_{e}=\omega_{m}+\omega_{s l} \\
\psi_{R}=L_{m} i_{m}
\end{array}\right.
\end{aligned}
$$

where:

$$
\left\{\begin{array}{l}
L_{\sigma}=\left(\frac{L_{S} L_{R}-L_{m}^{2}}{L_{R}}\right) \\
L_{S} / L_{R}: \text { Stator/Rotor_inductance } \\
L_{m} \quad: \text { Magnetizing_inductance } \\
T_{R} \quad: \text { Rotor_time constant }
\end{array}\right.
$$

From (8)-(10), we can determine the stator current components on the $[x-y]$ axis through in:

$\frac{d i_{S y}}{d t}=\frac{1}{L_{\sigma}}\left[-R_{S} i_{S y}-L_{S} \omega_{e} i_{S x}+u_{S y}\right]$

$i_{S x}=\frac{\omega_{e} L_{\sigma} i_{S y}+u_{S x}}{R_{S}}$

The rotor slip speed can be determined as the following:

$$
\omega_{s l}=\frac{L_{m} i_{S y}}{T_{R} \psi_{R}}=\frac{i_{S y}}{T_{R} i_{m}}
$$

Due to the magnetic current is keep as a constant value in the FOC technique; therefore, we can apply the reference magnetic currents $\left(i_{m}, i_{s x}\right)$ and reference voltage on the y-axis to replace the actual signals in the differential equations. As a result, we can obtain the estimated equations for virtual stator currents based on the rotor slip rotor, as shown in:

$$
\begin{aligned}
& \frac{d i_{S y \_e s t}}{d t}=\frac{1}{L_{\sigma}}\left[-\left(R_{S}+\frac{L_{S} i_{S x}^{*}}{T_{R} i_{m}^{*}}\right) i_{S y_{-} e s t}-L_{S} p \omega_{e n} i_{S x}^{*}+u_{S y}^{*}\right] \\
& i_{S x_{-} e s t}=\frac{\left(p \omega_{\text {en }}+\omega_{\text {Sl_est }}\right) L_{\sigma} i_{S y_{\_} e s t}+u_{S x}^{*}}{R_{S}}
\end{aligned}
$$

Where:

$$
\omega_{\text {sl_est }}=\frac{i_{\text {Sy_est }}}{T_{R} i_{m}^{*}}
$$

The block diagram of the FOC used the virtual stator current is shown in Figure 3. AS shown in (14), (15), (16) are applied in the "Virtual current estimator block" for generating the estimated stator current instead of feedback current signals from sensors. The reference voltages, reference currents, and the rotor speed signal are used as the input signals of the estimator. The PI controllers use the reference signals and the estimated signals to modulate the control voltage for the switching inverter. As a result, the speed control using FOC strategy of IMD is implemented with only a speed sensor in the drive system. The simulations 
have been implemented to prove the high performance of the proposed technique in many operation conditions.

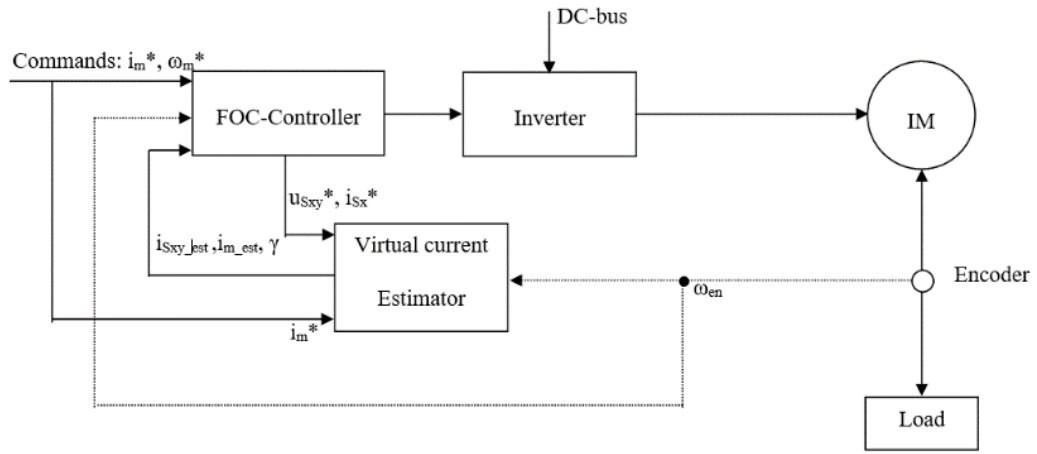

Figure 3. Block diagram of IMD using FOC with the virtual current

\section{SIMULATION RESULTS}

Simulations are performed in many operating conditions to verify the feasibility of virtual current estimation method in the speed control of IM. The simulations using a three-phase IM with a rated power of $2.2 \mathrm{~kW}$ and a rated voltage $\mathrm{D} / \mathrm{Y}$ of $230 \mathrm{~V} / 400 \mathrm{~V}$ are implemented for speed control. The parameter of IM applied to the simulations is described in Table 1

Table 1. Parameters of the IM

\begin{tabular}{lccr}
\hline \multicolumn{1}{c}{ Description } & Symbol & Unit & \multicolumn{1}{c}{ Value } \\
\hline Rated_Torque & $\mathrm{T}_{\mathrm{n}}$ & $\mathrm{Nm}$ & 14.8 \\
Rated_Speed & $\omega_{\mathrm{n}}$ & $\mathrm{rpm}$ & 1420 \\
Rated stator current D/Y & $\mathrm{I}_{\mathrm{S}}$ & $\mathrm{A}$ & $8.43 / 4.85$ \\
Stator/Rotor_Resistance & $\mathrm{R}_{\mathrm{S}} / \mathrm{R}_{\mathrm{R}}$ & $\Omega$ & $3.179 / 2.118$ \\
Magnetizing_Inductance & $\mathrm{L}_{\mathrm{m}}$ & $\mathrm{H}$ & 0.192 \\
Number of pole pairs & $\mathrm{p}$ & - & 2 \\
Stator/Rotor_Inductance & $\mathrm{L}_{\mathrm{S}} / \mathrm{L}_{\mathrm{R}}$ & $\mathrm{H}$ & $0.209 / 0.209$ \\
\hline
\end{tabular}

The control model in Figure 4 is used to implement the simulations for speed control of IMD based on the FOC technique in various conditions

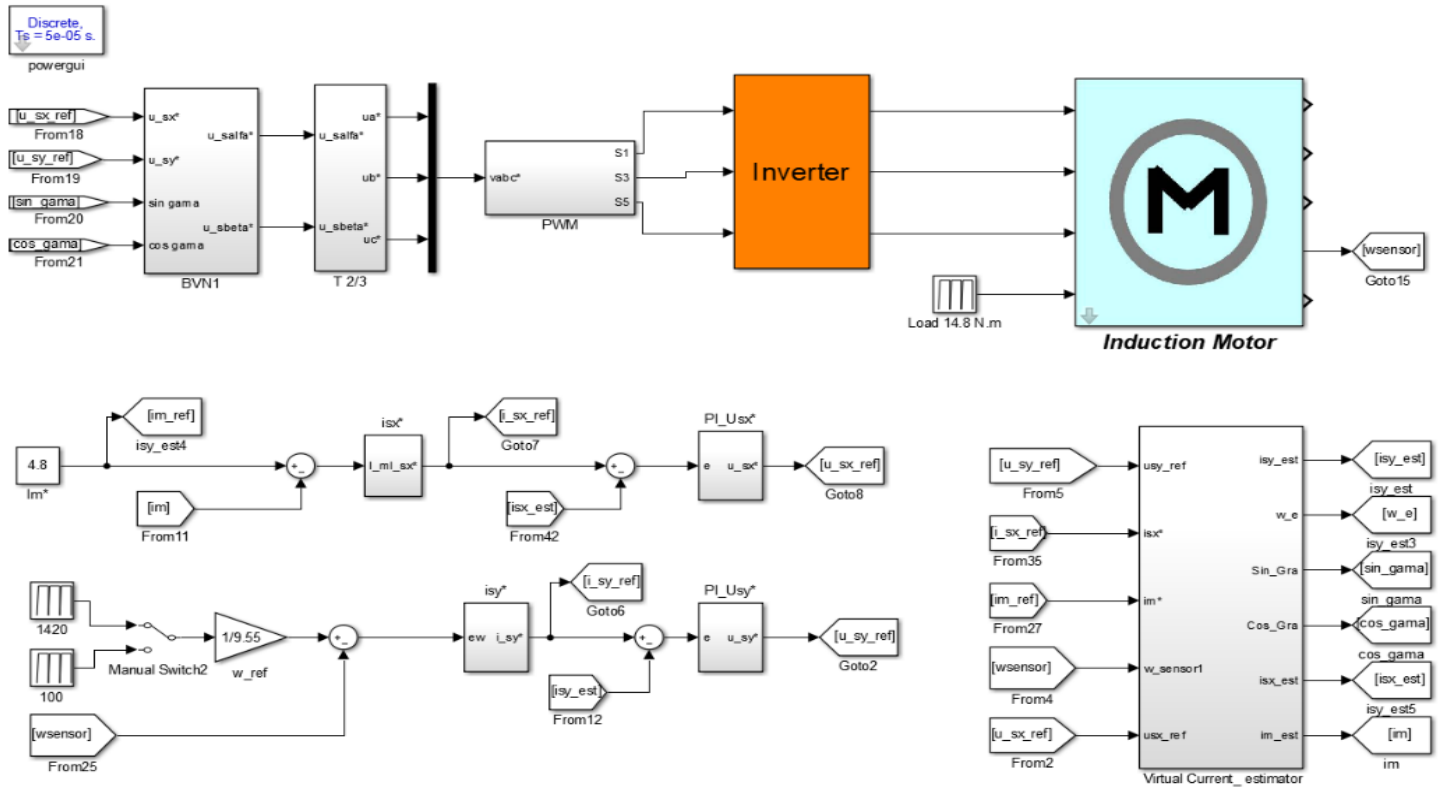

Figure 4. Simulation model of IMD using FOC technique without current sensors

A field-oriented control method using the virtual currents for the induction motor drive (Cuong Dinh Tran) 
In the first case, the performance of IMD using the FOC technique without current sensors is verified in the rated operating condition. In this simulation, the reference speed and the load torque are set as a ramp from zero to rated value for a 1-second interval, then kept as a constant corresponding rated value during operation, as shown in Figures 5(a)-(d). The IM operated stably, and the response speed of the IMD (blue) quickly reaches the reference value (red) after a short transient, as shown in Figure 5 (a). Figure 5 (b) indicates the virtual stator current of the estimator in the operation process of the IMD. Figure 5 (c) demonstrated the equivalence in shape and magnitude of the virtual (red) and actual (blue) current components during the operation of IMD. The electrical torque is increased quickly to push the motor speed up to the setting value; after the rotor speed reaches the stable value, the electrical torque keeps balance with the load torque, as shown in Figure 5 (d).

The proposed sensorless method is verified in the operating condition at a low speed in the next case. A reference speed is set as a ramp from zero to a value of $100 \mathrm{rpm}$ corresponding to a ramp load torque of $5 \mathrm{Nm}$ applied, as shown in Figures 6(a)-(d). The simulation shows that the IMD has a quick response rotor speed corresponding to the operation condition. Figure 6 (a) proved the suitability of the proposed method in speed control during the operation of the system at a low speed. The estimated current of the proposed method has a similar form as the measured current in Figures 6 (b), and 6 (c). Therefore, the FOC loop using the estimated current still effectively control the rotor speed equivalent to the FOC loop utilizing the sensor's feedback current signal. Figure 6 (d) describes the electrical torque and load torque of 5 (N.m) in the operation of the IMD system.

Through the above typical cases, IMD using virtual current can work effectively at the rated speed as well as a low speed. The simulation results have shown that the virtual stator current of the estimation method is similar to the actual current of the IMD. Thus, the FOC technique with virtual stator current based on the rotor slip has been proved feasible in the speed control of IMD over a wide speed range.

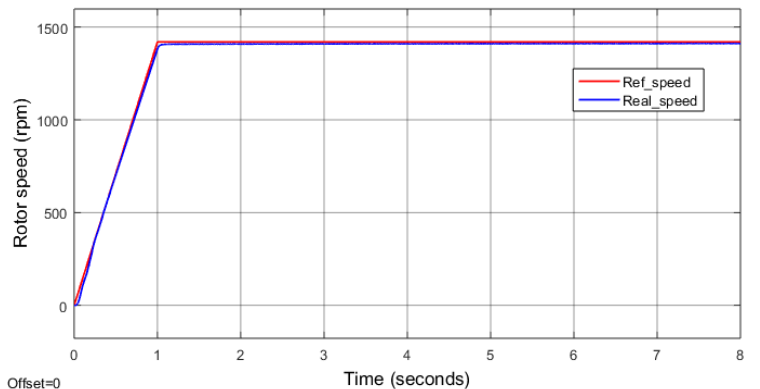

(a)

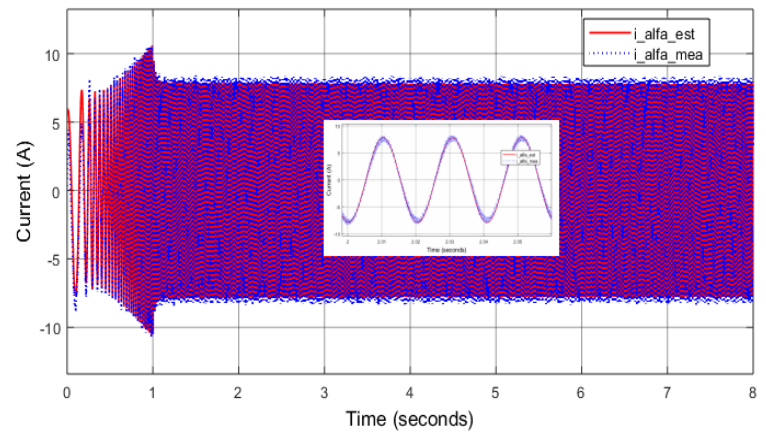

(c)

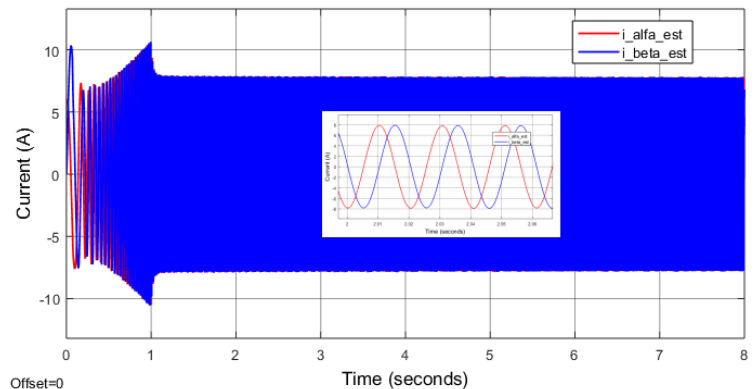

(b)

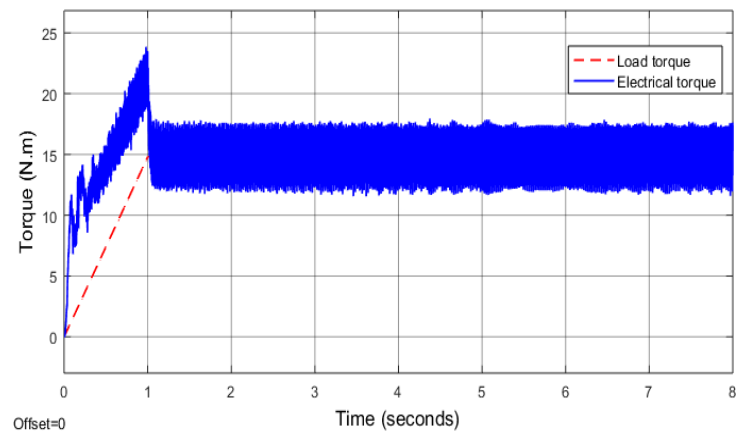

(d)

Figure 5. Performance of the IMD at $1420 \mathrm{rpm}$ with the virtual-current in a rated-load of $14.8 \mathrm{Nm}$; (a) reference and real speed, (b) virtual stator current, (c) virtual and real-alpha currents, (d) torques of IMD 


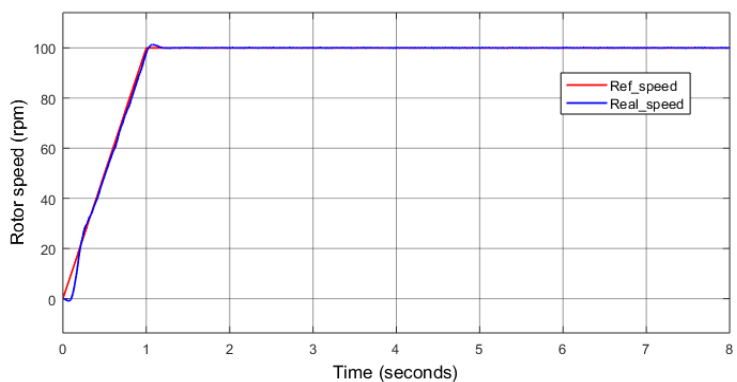

(a)

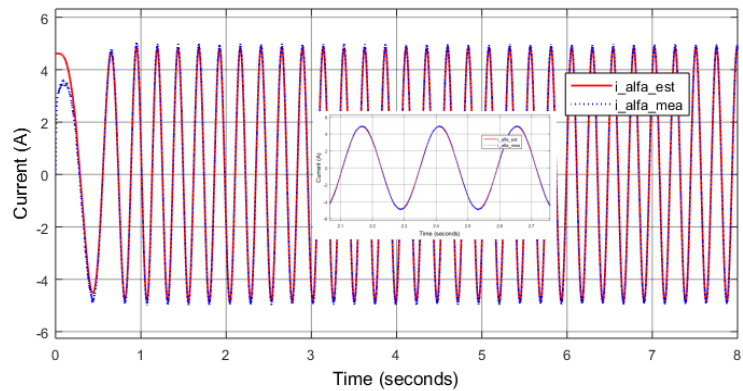

(c)

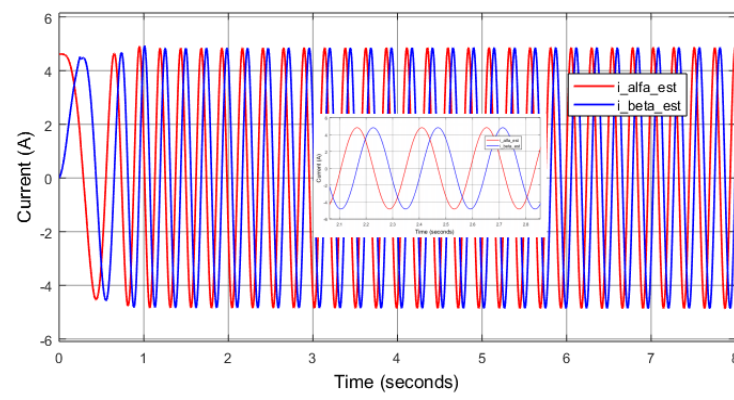

(b)

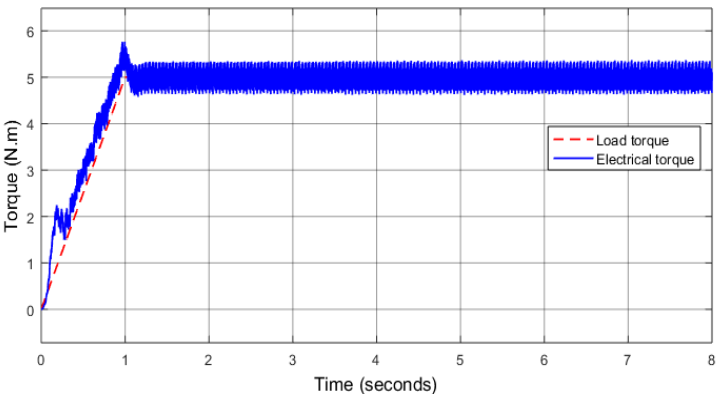

(d)

Figure 6. Performance of the IMD at $100 \mathrm{rpm}$ with the virtual-current in a load of $5 \mathrm{Nm}$; (a) reference and real speed, (b) virtual stator current, (c) virtual and real alpha-currents, (d) torques of IMD

\section{CONCLUSION}

This paper presents another approach in estimating a virtual stator current vector to control the motor speed based on the FOC technique. The virtual stator currents calculated based on the rotor slip combining the reference signals are used instead of the feedback current signal in the FOC control loop. The virtual currents have indicated the equivalence in shape and magnitude with the measured current in simulation results. Consequently, an IMD system using the FOC strategy to control the motor speed without current sensors has worked reliably during operation. Furthermore, the FOC method using virtual currents can also be applied as a backup solution in the reconfiguration phase of the current sensor fault-tolerant control techniques.

\section{ACKNOWLEDGEMENTS}

This research is funded by Saigon University, Vietnam, 2021, under grant number CS2021-17.

\section{REFERENCES}

[1] T. F. Chan and K. Shi, "Applied intelligent control of induction motor drives," in IEEE PRESS, 1st ed, John Wiley \& Sons, 2011, pp. 1-7.

[2] J. M. Peña and E. V. Díaz, "Implementation of V/f scalar control for speed regulation of a three-phase induction motor," in 2016 IEEE ANDESCON, Oct. 2016, pp. 1-4, doi: 10.1109/ANDESCON.2016.7836196.

[3] A. Smith, S. Gadoue, M. Armstrong, and J. Finch, "Improved method for the scalar control of induction motor drives," IET Electric Power Applications, vol. 7, no. 6, pp. 487-498, 2013, doi: 10.1049/iet-epa.2012.0384.

[4] T. H. dos Santos, A. Goedtel, S. A. O. da Silva, and M. Suetake, "Scalar control of an induction motor using a neural sensorless technique," Electric Power Systems Research, vol. 108, pp. 322-330, 2014, doi: 10.1016/j.epsr.2013.11.020.

[5] Z. Zhang and A. M. Bazzi, "Robust Sensorless Scalar Control of Induction Motor Drives with Torque Capability Enhancement at Low Speeds," 2019 IEEE International Electric Machines \& Drives Conference (IEMDC), 2019, pp. 1706-1710, doi: 10.1109/IEMDC.2019.8785159.

[6] G. Kohlrusz and D. Fodor, "Comparison of scalar and vector control strategies of induction motors," Hungarian Journal of Industry and Chemistry., vol. 39, no. 2, pp. 265-270, 2011, doi: 10.1515/422.

[7] M. Usama and J. Kim, "Vector Control Algorithm Based on Different Current Control Switching Techniques for Ac Motor Drives," in E3S Web of Conferences, vol. 152, p. 03009, 2020, doi: 10.1051/e3sconf/202015203009.

[8] A. Popov, V. Lapshina, F. Briz and I. Gulyaev, "Dynamic operation of FOC induction machines under current and voltage constraints," 2017 19th European Conference on Power Electronics and Applications (EPE'17 ECCE Europe), 2017, pp. P.1-P.10, doi: 10.23919/EPE17ECCEEurope.2017.8099296.

A field-oriented control method using the virtual currents for the induction motor drive (Cuong Dinh Tran) 
[9] A. Popov, V. Popova, I. Gulyaev and F. Briz, "Dynamic Response of FOC Induction Motors Using MTPA Considering Voltage Constraints," 2019 26th International Workshop on Electric Drives: Improvement in Efficiency of Electric Drives (IWED), 2019, pp. 1-5, doi: 10.1109/IWED.2019.8664402.

[10] W. Li, Z. Xu and Y. Zhang, "Induction motor control system based on FOC algorithm," 2019 IEEE 8th Joint International Information Technology and Artificial Intelligence Conference (ITAIC), 2019, pp. 1544-1548, doi: 10.1109/ITAIC.2019.8785597.

[11] F. Xie, Q. Wang and G. Li, "Optimization research of FOC based on PSO of induction motors," 2012 15th International Conference on Electrical Machines and Systems (ICEMS), 2012, pp. 1-4.

[12] H. A. Toliyat, E. Levi and M. Raina, "A review of RFO induction motor parameter estimation techniques," in IEEE Transactions on Energy Conversion, vol. 18, no. 2, pp. 271-283, June 2003, doi: 10.1109/TEC.2003.811719.

[13] H. Le-Huy, "Comparison of field-oriented control and direct torque control for induction motor drives," in Conference record of the 1999 IEEE industry applications conference. Thirty-forth IAS annual meeting (Cat. No. 99CH36370), vol. 2, Oct. 1999, pp. 1245-1252, doi: 10.1109/IAS.1999.801662.

[14] AN2388 Application note, "Sensor field oriented control (IFOC) of three-phase AC induction motors using ST10F276," ST Microelectronics, Oct. 2006, pp. 54. Available: https://www.st.com/resource/en/application_note/an2388-sensor-field-oriented-control-ifoc-of-threephase-acinduction-motors-using-st10f276-stmicroelectronics.pdf.

[15] C. D. Tran, P. Palacky, M. Kuchar, P. Brandstetter, and B. H, Dinh, "Current and Speed Sensor Fault Diagnosis Method Applied to Induction Motor Drive," IEEE Access., vol. 9, pp. 38660-38672, 2021, doi: 10.1109/ACCESS.2021.3064016.

[16] F. Wu, J. Zhao, Y. Liu and W. Cao, "A real-time sensor fault detection, isolation and reconfiguration method for vector controlled induction motors based on Extended Kalman Filter," 2016 International Symposium on Power Electronics, Electrical Drives, Automation and Motion (SPEEDAM), 2016, pp. 617-624, doi: 10.1109/SPEEDAM.2016.7525805.

[17] C. D. Tran, P. Brandstetter, M. C. H. Nguyen, S. D. Ho, B. H. Dinh, and P. N. Pham, "A robust diagnosis method for speed sensor fault based on stator currents in the RFOC induction motor drive," International Journal of Electrical and Computer Engineering., vol. 10, no. 3, pp. 3035-3046, 2020, doi: 10.11591/ijece.v10i3.pp30353046.

[18] C. Chakraborty and V. Verma, "Speed and Current Sensor Fault Detection and Isolation Technique for Induction Motor Drive Using Axes Transformation," in IEEE Transactions on Industrial Electronics, vol. 62, no. 3, pp. 19431954, March 2015, doi: 10.1109/TIE.2014.2345337.

[19] C. D. Tran, P. Brandstetter, M. Kuchar, and S. D. Ho, "A Novel Speed and Current Sensor Fault-Tolerant Control Based on Estimated Stator Currents in Induction Motor Drives," International Review of Electrical Engineering., vol. 15, no. 5, pp. 344-351, 2020, doi: 10.15866/iree.v15i5.17937.

[20] G. Barba, L. Glielmo, V. Perna and F. Vasca, "Current sensorless induction motor observer and control for hybrid electric vehicles," 2001 IEEE 32nd Annual Power Electronics Specialists Conference (IEEE Cat. No.01CH37230), 2001, pp. 1224-1229 vol.2, doi: 10.1109/PESC.2001.954286.

[21] Y. Azzoug, R. Pusca, M. Sahraoui, A. Ammar, R. Romary and A. J. Marques Cardoso, "A Single Observer for Currents Estimation in Sensor's Fault-Tolerant Control of Induction Motor Drives," 2019 International Conference on Applied Automation and Industrial Diagnostics (ICAAID), 2019, pp. 1-6, doi: 10.1109/ICAAID.2019.8934969.

[22] V. Verma, "Current sensorless vector controlled induction motor drive," IAES International Journal of Robotics and Automation, vol. 8, no. 1, pp. 52-67, 2019, doi: 10.11591/ijra.v8i1.pp52-67.

[23] M. Adamczyk and T. Orlowska-Kowalska, "Virtual Current Sensor in the Fault-Tolerant Field-Oriented Control Structure of an Induction Motor Drive," Sensors, vol. 19, no. 22, p. 4979, 2019, doi: 10.3390/s19224979.

[24] P. Brandstetter, M. Dobrovsky, M. Kuchar, C.S.T. Dong, and H. H. Vo, "Application of BEMF-MRAS with Kalman filter in sensorless control of induction motor drive," Electrical Engineering, vol. 99, no. 7, pp. 1151-1160, 2017, doi: 10.1007/s00202-017-0613-4.

[25] H. H. Vo, M. Kuchar, P. Brandstetter, "Application of fuzzy logic in sensorless induction motor drive with PWMDTC," Electrical Engineering, vol. 102, no. 1, pp. 129-140, 2019, doi: 10.1007/s00202-019-00810-z.

[26] M. Kuchar, P. Brandstetter and M. Kaduch, "Sensorless induction motor drive with neural network," 2004 IEEE 35th Annual Power Electronics Specialists Conference (IEEE Cat. No.04CH37551), 2004, pp. 3301-3305 Vol.5, doi: 10.1109/PESC.2004.1355058..

[27] V. T. Ha, N. T. Lam, V. T. Ha, and Q. V. Vo, "Advanced control structures for induction motors with ideal current loop response using field oriented control," International Journal of Power Electronics and Drive Systems, vol. 10, no. 4, pp. 1758-1771, 2019, doi: 10.11591/ijpeds.v10.i4.pp1758-1771.

[28] C. Laoufi, Z. Sadoune, A. Abbou, and M. Akherraz, "New model of electric traction drive based sliding mode controller in field-oriented control of induction motor fed by multilevel inverter," International Journal of Power Electronics and Drive Systems, vol. 11, no. 1, pp. 242-250, 2020, doi: 10.11591/ijpeds.v11.i1.pp242-250.

[29] M. K. Metwaly, et al., "Smart integration of drive system for induction motor applications in electric vehicles," International Journal of Power Electronics and Drive Systems, vol. 12, no. 1, pp. 20-28, 2021, doi: 10.11591/ijpeds.v12.i1.pp20-28.

[30] S. D. Ho, P. Brandstetter, P. Palacky, M. Kuchar, B. H. Dinh, and C. D. Tran, "Current sensorless method based on field-oriented control in induction motor drive," Journal of Electrical Systems, vol. 17, no. 1, pp. 62-76, 2021. 